\title{
Labor Outcomes of Implemented Evidence-Based Nursing Guideline during the Third Stage of Labor
}

\author{
Hanaa Abdel Hady Soliman, Mustfa A. Essa, Aziza T. Labib, Azza M. Hafez \& Nadia H. Ahmed
}

Assistant lecturer of Maternity and Obstetric Health Nursing Faculty of Nursing, Minia University, Egypt. Professor of Obstetric and Gynecology Medicine Faculty of Medicine, Minia University, Egypt. Professor of Maternity and Gynecology Health Nursing Faculty of Nursing - Ain shams, University, Egypt. Assistant Professor of Maternity and Obstetric Health Nursing Faculty of Nursing, Minia University. Egypt. Assistant Professor of Obstetric and Gynecology Health Nursing Faculty of Nursing, Assuit University. Egypt.

\begin{abstract}
Background: there is a question with obstetricians and health staff whether implemented evidence-based guideline, can affect labor outcomes. This study was conducted to implement evidence-based guideline practice during the third stage and all stages of labor will affect in reducing postpartum hemorrhage and giving better labor outcomes. Aim of the study: to determine effect of an evidence-based guideline on caring a woman during the third stage of labor and evaluate the labor outcome of evidence-based intervention (EBI). Materials and methods: Design: A quasi - experimental design. Tools structured interviewing sheet including socio-demographic data. Observational sheet including nursing practice, and Follow up sheet including assess blood loss. Setting: data collected from delivery unit, Minia University maternity Hospital. Sampling: simple random sampling, one hundred included in the study; divided into two equal (control and study group). Results: the study revealed that there were mean of blood loss after 1, 2, 3 hours of delivery can lower in the study than control group. On the other hand, There was a highly significant relationship between maternal outcome and their neonatal apgar score level $(\mathrm{P}=0.001)$. Conclusion and Recommendation: further researches are still needed to implemented guideline of nursing practices for childbirth and measures could be decreasing intra-postpartum hemorrhage and others complication.
\end{abstract}

\section{Keywords: Implemented of Evidence \&Based To (Labor Outcomes)}

\section{Introduction}

The process of labor involves more than the birth of newborn. Numerous physiological and psychological events occur that ultimately result in the birth of a newborn and the creation or expansion of the family. Labor is a complex multifaceted interaction between the mother and fetus. It is a series of process by which the fetus is expelled from the uterus. It is difficult to determine exactly why labor begins and what initiates it. Although several theories have been proposed to explain the onset and maintenance of labor, none of these has proved significant. (Kevin, 2009). It is widely believed that labor is influenced by a combination of factors including uterine stretch, progesterone withdrawal, increase of oxytocin sensitivity, and increased release of prostaglandins. In recent years cesarean rate has increased in the world. (Laifer \& Mayberry, 2009, Chengy, et al., 2010)

The third stage of labor commences after delivery of the infant and ends with delivery of the placenta and the membrane and thus is an event related to the process of labor. The physiologic processes of the third stage of labor are separation of placenta from the uterine wall and expulsion and finally contraction and retraction of the myometrium. (Johnson et al., 2009)

There has always been an asking question with obstetricians and health staff whether implementation of evidence based nursing guideline can affect on labor outcome; despite the lack of evidence based practices in nursing (EBP) is a framework for clinical practices that integrates the best available scientific evidence with nurses experts, patients performances and values to decide about health care of individual patient. EBP flourished in nursing and in health care generally. In spite of all various programs and strategies to promote the use of research finding, there is still a gap between theory and practices. (Levin, 2012)

One of the complications of the third stage is postpartum hemorrhage ( $\mathrm{PPH}$ ) which is the leading cause of maternal death, in both developing and industrialized countries (Berg et al., 2009). In the developing countries, the most common causes of maternal mortality are hemorrhage .In Egypt, maternal mortality ratio of 366 per 1000,000 live birth in Mina city. Of these maternal deaths, 83 were due to direct obstetric causes, Maternal Health Survey (2010). Another survey of registered death that was carried out in Menoufia Govemorate, Egypt. There were 190 maternal deaths per 100,000 live births and 45 maternal deaths per 100,000 married woman aged between 19- 40 years. Most of the maternal deaths were due to direct obstetric causes of which hemorrhage, was the main cause of death (Kevin, 2009 \& WHO, 2005). 
It is important to note that the development of an evidence base supported by the research is necessary before conclusions can be drawn about any particular practice. Evaluation requires systematic, standardized description of target population, program practices, and the theoretical relationship between clients served, practices and desired outcomes. Interventions must be shown to improve outcomes that are meaningful to participants, and that are measured objectively in research conducted by independent investigators (Center for Mental Health Services, 2010 \& Leff, et al., 2009).

Evidence-based practice helps nurses provide high quality patient care based on research and knowledge, optimal patient outcome, keeping practices current and relevant, and giving confidence in decision making. The goal of research course is to introduce nursing students to the basics of the scientific approach of research in the belief that they will be able to use the information produced to provide guidance to their nursing practice upon graduation. The idea behind clarifying the process of research is to enable practicing nurses to utilize the scientific thought process to make available and augment the nursing care which is provided to clients (Barwick, 2009).

In Egypt; postpartum hemorrhage is the attributed cause for $32 \%$ of all maternal deaths and $46 \%$ of all direct maternal death. Ninety nine percent of all PPH deaths were avoidable. There was no clear pattern to residence metropolitan woman had the lowest maternal mortality ratio for PPH (26per100.000), followed to an urban woman (37per100.000) and rural woman (58per100.000). (WHO, 2009)

Milasinovic et al., (2009), found that many postpartum complications cannot be underestimated. Among these complications are postpartum hemorrhage and puerperal sepsis which are the most common causes of maternal morbidity and mortality during postpartum period. So proper diagnosis, treatment and provision of postpartum nursing management to minimizing serious and reduce their effects on the mother's ability to function are essential.

Active management of the third stage of labor has been described as a package comprising the following interlocking interventions: administration of a prophylactic uterotonic after birth of the baby, and usually also early cord clamping and cutting, and controlled cord traction. Other definitions in this package include uterine massage, but without reference to the timing of cord clamping, management involves waiting for signs of separation and allowing the placenta to deliver spontaneously, or aided by gravity or nipple stimulation (Prendiville, et al., 2008) While there is agreement on the beneficial effects of active management of the third stage of labor for prevention of PPH, there are fewer consensuses on issues such as importance of the intervention's individual components, the best methods and the requirements for safe administration of this intervention under conditions of limited resources.

Recent evidence suggests that the effect of early versus late cord clamping may be different for preterm and term infants, because normal physiological process of transfer is completed within the first 1-2 minutes of birth for the majority of these infants, and therefore the late of cord clamping can lead to risk of postpartum hemorrhage (Rabe et al., 2006) The umbilical cord can be clamped immediately after birth or at a later moment, and this may have effect on the mother and the infant (Prendiville \& Elbourne, 2006, Omyma, 2010) found that there was no evidence if a significant effect of the timing of cord clamping on the incidence of postpartum hemorrhage or on feto-maternal transfusion.

Evidence-based practice guideline shows that the cord should be checked for bleeding or oozing during the early hours after birth. The cord must be cleaned with water or alcohol and kept it clean and dry in the best method of cord care. The diaper is folded below the cord to keep the cord free from contamination by urine. (WHO, 2009) Evaluation of patient progress and outcomes continue throughout the fourth stage of labors as a result of comprehensive nursing care during intra-partum period, the following outcomes may be anticipated. The mother physical and psychological well-being has been maintained and supported. The baby's physical psychological wellbeing has been protected and supported. The mother and her baby have had a safe birth. (Cunnungham, et al., 2009)

\section{Significance of Study}

The third stage of labor is crucial phase for both the mother and new born as maternal and new born compromise may occur due to poor or inadequate care provided by the practitioners. So Nurses must have the skills, Knowledge, and practice to apply active care during the third stage of labor as recommended by (Donna, 2008). Because of increasing high mortality rate due to women with PPH and poor quality of care, in the study in 2010 reported that $30 \%$ of maternal death are due to $\mathrm{PPH}$, in spite of the new technology in health filed. This study was conducted and carried out to determine and compare the labor outcome of implemented evidence-based guideline between study and control group in maternity university hospital. 


\section{Aim of the Study}

The aim of the study was to determine effect of evidencebased guideline on caring a woman during the third stage of labor and to evaluate the labor outcomes of evidencebased intervention

\section{Subject and methods \\ Research design}

A quasi - experimental design was utilized in this study.

\section{Setting}

This study was conducted at the labor and delivery unit in the department of obstetrics and gynecology, Minia University maternity Hospital. The numbers of deliveries were 5940 in 2010, including normal and abnormal deliveries. There are ten nurses in the labor ward arranged as follows five nurses at the morning shift, three nurses at the evening shift, and two nurses at the night shift caring for low risk cases. The nurse $\backslash$ patient ratio is about one nurse for every 5-10 patients. This hospital is affiliated to the university and provides free health care services to rural and urban population in the governorate of Minia. Since 2008 , women have to pay for the services provided.

\section{Subject}

After exclusion of women who didn't match the inclusion criteria of this study and who attended to the labor and delivery unit, in Minia University maternity hospital, this hospital provides free health care services to rural and urban population, number of deliveries were 5940 in 2010 including normal and abnormal deliveries, the sample was simple random consisting of 100 natal women randomly selected and divided into two equal groups, 50 in the control group and 50 in the study group.

\section{- Inclusion criteria}

$\circ$ Full-term pregnancy.

○ Normal labor.

○ Primipara or Multipara.

- Exclusion criteria

$\circ$ Twins and multipal pregnancy.

$\circ$ Heart disease.

$\circ$ Diabetes mellitus.

$\circ$ Pregnancy induced hypertension.

$\circ$ Postdata.

Tools for data collection

Three tools were used in this study

Interviewing questionnaire sheet

It was developed by the researcher to collect the data related to socio-demographic as age, educational level, occupation, menstrual history, previous post and present obstetrical profile as; parity, gravidity, mode of previous and present delivery, duration and pattern of care in each stage of labor,

Note: gestional age of the fetus was collected from the mother or sonar to all of them and was transferred to weeks.
Observational checklist: it was developed by the researcher to collect data related to pattern of care provided during delivery through Assessment of care; History taking, physical examination such as abdominal and pelvic examination, uterine contraction, frequent position change, relaxation and breathing exercise, back massage. Implementation care as; Use partogram to assess labor progress, hearing and count fetal heart rate, descent of presenting part, help in repair episiotomy, observe signs of placental separation, administrate oxytocin and newborn assessment through Apgar scoring, suction \& clear the airway, cutting the cord and cord care, encourage newborn for immediate suckling, and breast feeding

Scoring of postpartum hemorrhage including

- High score of PPHg which included (primary prevention by using utero tonic drugs and non-surgical treatment, anti-fibro genic drug)

- Medium score of PPHg including (stabilization e.g. anti shocked garment, blood transfusion, blood products and surgical treatment)

- Low score of PPHG including (Predictive screening and diagnosis) to manage increasing blood loss before the woman has PPHg

Apgar scoring: It was developed with the purpose of evaluating the physical condition of the newborn. It is usually used at the first and fifth minutes after delivery. Apgar score includes heart rate, respiratory effort, muscles tone, reflexes, and color of newborn skin, the newborn receive a total score ranging from 0 to 10

Test description: This test was developed by good enough in 1976 to evaluate the labor outcomes of evidence-based intervention, it was composed of five items in which the researcher implemented caring for women at labor such as uterine massage and check of $\mathrm{Hg}$ level.

Test instructions: Instructions of the test were given orally in the of assignment of the studied sample to exclude what might exist in form of small group.

Ethical considerations: Before the implementation of the study an official permission was obtained from the director of the obstetric ward in Minia University hospital, and from mothers after full explanation of the research idea, the procedure and right for privacy and confidentiality was taken.

\section{Procedures}

Field work

The study was conducted from the 1st of January 2010 to the end of July 2010. The data were collected in two main phases, normal assessment phase, and intervention phase.

Assessment Phase: Mothers were interviewed to collect data related to socio-demographic characteristics, the past and present obstetric profile. Interviewing was done at the labor unit. The investigator faced the mother and asked her questions in Arabic and recorded mother's answers in the sheet. The interview listed for 20-30 minutes for each 
mother. The investigator visited the delivery room two days weekly from 8 am to $2 \mathrm{pm}$ to interview the study sample women. The first day of the field work was allocated to the control group, while the second day was for the intervention group. The purpose of the study was explained, and then the mother gave her verbal consent to participate in the study

\section{Intervention Phase}

- After obtaining the baseline data of first and second stage of labor was carried out of mothers related to evidence-based including: history, physical assessment (local and general), labor progress through, care provided to woman during first and second stage of labor that, included: duration of second stage which detected from full dilation of the cervix to complete delivery of the fetus, maternal position during second stage of labor, was handler of delivery, stretching of perineum, supported perineum, massage with or without lubricant, maintain flexion of the head, delivery head between contraction to avoid tear and laceration occurrence .

- Hearing FHR and oxytocin administration, vital signs (pulse, respiration, and temp.), duration of 3rd stage of labor through calculating the time between the delivery of the fetus to the delivery of the placenta, vaginal and premium examination was also carried out to assess if premium is intact or not, under complete aseptic technique

- Assess the lower abdominal segment by using downward pressure to inspect the uterine tone and position after placental delivery, usually, in mid-way between the umbilicus and symphysis pubis and well contracted.

- The investigator controlled traction of the umbilical cord and immediate cutting of cord.

- During the $1^{\text {st }}$ two hours after placental delivery and repairing of perineum, the mother was assessed for vital signs (especially pulse). Uterine massage was carried out and administration of oxytocin to maintain the uterine tone and contractility of the uterus to avoid PPHg.

- Other nursing interventions performed by the investigator including maintaining the uterus well contraction, nipple stimulation or by immediate breast feeding of the new born; which more successful to assist the uterine muscle to be more contracted

- Massage and compression of the uterus were done manually: Initially, the investigator started by fundal massage for 10 minutes and giving 10-20 IU of oxytocin if the cause of hemorrhage was atonic uterus

\section{Statistical analysis}

Data were analyzed using the statistical package for social science (SPSS) version (windows Microsoft) continuous data were expressed as frequency, percentage, mean, SD, and the range. Discrete data were expressed as frequency and percentage. Comparison between variables was done using Chi-square test, T-test. The last test was used to identify variables that could be predictors of maternal outcomes. 


\section{Results}

Table (1): Distribution of Mothers According to their Socio-demographic Characteristics (n=100).

\begin{tabular}{|c|c|c|c|c|c|c|}
\hline & \multicolumn{2}{|c|}{$\begin{array}{l}\text { Study } \\
(\mathbf{n}=\mathbf{5 0})\end{array}$} & \multicolumn{2}{|c|}{$\begin{array}{c}\text { Control } \\
(n=50)\end{array}$} & \multirow{2}{*}{$\begin{array}{c}\begin{array}{c}\text { Total } \\
(\mathrm{n}=100)\end{array} \\
\text { No }\end{array}$} & \multirow[t]{2}{*}{$\mathrm{X} 2, \mathrm{~T}$ test } \\
\hline Items & No & $\%$ & No & $\%$ & & \\
\hline \multicolumn{7}{|l|}{ Age Range (in years) } \\
\hline $16-20$ & 10 & 20 & 8 & 16 & 18 & \\
\hline $21-25$ & 15 & 30 & 16 & 32 & 31 & \\
\hline $26-30$ & 14 & 28 & 11 & 22 & 25 & \\
\hline $31-35$ & 6 & 12 & 6 & 12 & 12 & \\
\hline $36-40$ & 3 & 6 & 5 & 10 & 8 & \\
\hline $41-45$ & 2 & 4 & 4 & 8 & 6 & \\
\hline Mean + SD & \multicolumn{2}{|c|}{$26.3 \pm 6.6$} & \multicolumn{2}{|c|}{$27.0 \pm 7.0$} & & $\mathbf{T}=\mathbf{0 . 0 5}$ \\
\hline \multicolumn{7}{|l|}{ Educational Level } \\
\hline Illiterate & 11 & 22 & 10 & 20 & 21 & \multirow{4}{*}{$\begin{array}{c}X 2=2.4 \\
>0.05\end{array}$} \\
\hline Basic education & 19 & 38 & 19 & 38 & 38 & \\
\hline Secondary school & 14 & 28 & 13 & 26 & 27 & \\
\hline University & 6 & 12 & 8 & 16 & 14 & \\
\hline \multicolumn{7}{|l|}{ Occupation } \\
\hline Housewife & 36 & 72 & 32 & 64 & 68 & \multirow{2}{*}{$\begin{array}{c}X 2=3.2 \\
>0.05\end{array}$} \\
\hline Employee & 14 & 38 & 18 & 36 & 32 & \\
\hline
\end{tabular}

- Insignificant * significant

Table (2): Distribution of Mothers According to their Mode of Previous Delivery (n=51).

\begin{tabular}{|l|c|c|c|c|c|c|c|}
\hline & \multicolumn{2}{|c|}{$\begin{array}{c}\text { Study } \\
\mathbf{n = 2 7}\end{array}$} & $\begin{array}{c}\text { Control } \\
\mathbf{n = 2 4}\end{array}$ & $\begin{array}{c}\text { Total } \\
\mathbf{n = 5 1}\end{array}$ & $\begin{array}{c}\text { Total } \\
\mathbf{\%}\end{array}$ & X2- test \\
\hline \multicolumn{1}{|c|}{ Mode of Previous Delivery } & No & $\%$ & No & $\%$ & & & \\
\hline Normal vaginal delivery without episiotomy & 6 & 11.8 & 5 & 9.8 & 11 & 21.6 & $0.23 /$ \\
\hline Vaginal delivery with episiotomy & 20 & 39.2 & 17 & 33.3 & 37 & 72.5 & $>0.05$ \\
\hline Instrumental delivery & 1 & 2.0 & 2 & 3.9 & 3 & 5.9 & \\
\hline
\end{tabular}

Table (3): Distribution of Mothers According to Assessment during Third Stage of Labor $(n=100)$.

\begin{tabular}{|c|c|c|c|c|c|c|}
\hline \multirow{2}{*}{ Items } & \multicolumn{2}{|c|}{ Study/ $n=50$} & \multicolumn{2}{|c|}{ Control/ $\mathrm{n}=\mathbf{5 0}$} & \multirow{2}{*}{$\frac{\text { Total }}{\text { No }}$} & \multirow{2}{*}{$\begin{array}{c}\text { X2 } \\
\text { Test }\end{array}$} \\
\hline & No & $\%$ & No & $\%$ & & \\
\hline \multicolumn{7}{|c|}{ Method of Management of Third Stage of Labor } \\
\hline Active & 47 & 94 & 35 & 70 & 82 & \multirow{2}{*}{$13.6^{*}$} \\
\hline Expectant & 3 & 6 & 15 & 30 & 18 & \\
\hline \multicolumn{7}{|l|}{ Placental Condition } \\
\hline Complete & 49 & 98 & 40 & 80 & 89 & \multirow{2}{*}{$8.3^{*}$} \\
\hline Incomplete & 1 & 2 & 10 & 20 & 11 & \\
\hline \multicolumn{7}{|l|}{ Presence of episiotomy } \\
\hline Yes & 15 & 30 & 21 & 42 & 36 & \multirow{2}{*}{$6.5^{*}$} \\
\hline No & 33 & 66 & 27 & 54 & 60 & \\
\hline Not Applicable & 2 & 4 & 2 & 4 & 4 & -- \\
\hline
\end{tabular}


Table (4): Distribution of Mothers According to Duration of Third Stage of Labor ( $n=100)$.

\begin{tabular}{|c|c|c|c|c|c|}
\hline \multirow{2}{*}{ Items } & \multicolumn{2}{|c|}{ Study } & \multicolumn{2}{|c|}{ Control } & \multirow{2}{*}{$\begin{array}{c}\text { T- } \\
\text { Test }\end{array}$} \\
\hline & Mean & \pm SD & Mean & $\pm \mathrm{SD}$ & \\
\hline Duration of Third Stage of Labor & 12.6 & 5.3 & 19.4 & 7.9 & $5.04 *$ \\
\hline
\end{tabular}

- Insignificant * significant

Table (5): Distribution of Mothers According to Tone of Uterus after 1hrs, 2hrs, and 3hrs of Delivery $(\mathrm{N}=\mathbf{1 0 0})$.

\begin{tabular}{|c|c|c|c|c|c|c|c|c|c|c|c|}
\hline \multirow{3}{*}{ Items } & \multicolumn{4}{|c|}{ Study/ N=50 } & \multirow{3}{*}{$\begin{array}{c}\text { Total } \\
\text { No } \\
\text { X2 }\end{array}$} & \multicolumn{4}{|c|}{ Control/ $\mathbf{N}=\mathbf{5 0}$} & \multirow{3}{*}{$\begin{array}{c}\text { Total } \\
\text { No }\end{array}$} & \multirow{3}{*}{$\begin{array}{c}\text { X2 } \\
\text { Test }\end{array}$} \\
\hline & \multicolumn{2}{|c|}{ Contracted } & \multicolumn{2}{|c|}{ Soft } & & \multicolumn{2}{|c|}{ Contracted } & \multicolumn{2}{|c|}{ Soft } & & \\
\hline & No & $\%$ & No & $\%$ & & No & $\%$ & No. & $\%$ & & \\
\hline \multicolumn{12}{|c|}{ Tone of the Uterus } \\
\hline $1 \mathrm{hr}$ & 19 & 38 & 31 & 62 & 28 & 9 & 18 & 41 & 82 & 72 & $<11.5^{*}$ \\
\hline $2 \mathrm{hr}$ & 21 & 42 & 29 & 58 & 32 & 11 & 22 & 39 & 78 & 68 & $<11.7 *$ \\
\hline $3 \mathrm{Hr}$ & 50 & 100 & 0 & 0 & 85 & 35 & 70 & 15 & 30 & 15 & $<19.2^{*}$ \\
\hline
\end{tabular}

Table (6): Distribution of Mothers in the Study and Control Groups According to Amount of Blood Loss after, $1 \mathrm{hrs}, 2 \mathrm{hrs}$, and $3 \mathrm{hrs}$ of Delivery $(\mathrm{n}=100)$.

\begin{tabular}{|c|c|c|c|c|c|c|c|}
\hline \multirow{2}{*}{$\begin{array}{c}\text { Amount of Blood } \\
\text { Loss }\end{array}$} & \multicolumn{2}{|c|}{ Study $/ \mathbf{n}=\mathbf{5 0}$} & \multicolumn{2}{|c|}{ Control $/ \mathrm{n}=\mathbf{5 0}$} & \multicolumn{2}{|c|}{ Total $/ \mathbf{n}=100$} & \multirow[t]{2}{*}{ T-Test } \\
\hline & Mean & $\pm \mathrm{SD}$ & Mean & $\pm \mathrm{SD}$ & Mean & $\pm \mathrm{SD}$ & \\
\hline - $1 \mathrm{hr}$ & 350.6 & 321 & 704.8 & 489.4 & 1055.40 & 978.8 & $68.3^{* *}$ \\
\hline - $2 \mathrm{hr}$ & 120.5 & 75.4 & 242.4 & 115.4 & 362.9 & 190.8 & $47.1 * *$ \\
\hline - $3 \mathrm{hr}$ & 52.1 & 30.3 & 62.6 & 48.4 & 118.7 & 78.7 & $21.5^{* *}$ \\
\hline
\end{tabular}

Table (7): Relationship between Postnatal Factors and Period of Recovery and Discharge (n=100).

\begin{tabular}{|c|c|c|c|}
\hline \multirow{2}{*}{ Item } & \multicolumn{3}{|c|}{ Amount of blood loss } \\
\hline & Mean & \pm SD & $\mathbf{T} \& \mathbf{P}$ \\
\hline \multicolumn{4}{|l|}{ Mode of Delivery } \\
\hline Vaginal delivery without episiotomy & 54.00 & 21.13 & \multirow{3}{*}{$\mathrm{T}=3.371, \mathrm{P}=0.039 *$} \\
\hline Vaginal delivery with episiotomy & 27.27 & 27.32 & \\
\hline Instrumentals & 22.12 & 23.17 & \\
\hline \multicolumn{4}{|c|}{ Method of Management of Third Stage of Labor } \\
\hline Active & 45.56 & 36.75 & \multirow{2}{*}{$\mathrm{T}=3.196, \mathrm{P}=0.002 * *$} \\
\hline Expectant & 24.03 & 22.71 & \\
\hline \multicolumn{4}{|l|}{ Placental condition } \\
\hline Complete & 51.00 & 27.77 & \multirow{2}{*}{$\mathrm{T}=4.722, \mathrm{P}=0.001 * *$} \\
\hline Incomplete & 22.05 & 23.52 & \\
\hline \multicolumn{4}{|l|}{ Presence of tears } \\
\hline Yes & 18.39 & 22.02 & \multirow{2}{*}{$\mathrm{T}=3.001, \mathrm{P}=0.003 * *$} \\
\hline No & 34.40 & 28.52 & \\
\hline \multicolumn{4}{|l|}{ Blood Transfusion } \\
\hline Yes & 8.04 & 8.9 & \multirow{2}{*}{$\mathrm{T}=8.22, \mathrm{P}=0.001 * *$} \\
\hline No & 70.60 & 36.21 & \\
\hline
\end{tabular}

* significant ** highly significant 
Table (8): Postnatal Factors by the Amount of Blood Loss after 3hrs of Labor.

\begin{tabular}{|c|c|c|c|}
\hline \multirow{2}{*}{ Item } & \multicolumn{2}{|c|}{ Period of Recovery and Discharge } & \multirow{2}{*}{$\mathbf{T} \& \mathbf{P}$} \\
\hline & Mean & $\pm \mathrm{SD}$ & \\
\hline \multicolumn{4}{|l|}{ Placental condition } \\
\hline Complete & 96.38 & 57.80 & \multirow{2}{*}{$\mathrm{T}=-6.299, \mathrm{P}<0.001 * *$} \\
\hline Incomplete & 199.52 & 91.79 & \\
\hline \multicolumn{4}{|l|}{ Presence of tears } \\
\hline Yes & 146.89 & 84.66 & \multirow{2}{*}{$\mathrm{T}=-3.970, \mathrm{P}=0.001 * *$} \\
\hline No & 89.35 & 49.45 & \\
\hline \multicolumn{4}{|l|}{ Tone of the Uterus } \\
\hline Contracted & 98.87 & 50.55 & \multirow{2}{*}{$\mathrm{T}=-8.22, \mathrm{P}<0.001 * *$} \\
\hline Soft & 246.92 & 106.17 & \\
\hline \multicolumn{4}{|l|}{ Mode of delivery } \\
\hline Vaginal delivery without episiotomy & 129.71 & 73.58 & \multirow{3}{*}{$\mathrm{T}=0.333, \mathrm{P}<0.72$} \\
\hline Vaginal delivery with episiotomy & 115.07 & 75.05 & \\
\hline Istrsmentals & 132.50 & 135.18 & \\
\hline \multicolumn{4}{|c|}{ Method of management of third stage of labor } \\
\hline Active & 107.03 & 68.93 & \multirow{2}{*}{$\mathrm{T}=-3.21, \mathrm{P}=0.002 * *$} \\
\hline Expectant & 170.00 & 98.64 & \\
\hline
\end{tabular}

** highly significant

Table (1): Shows that woman in the two groups had insignificant differences regarding their age, education, and occupation. The same table shows that their mean ages were 26.3, 27 years old respectively. The majority of them $(72 \%, 64 \%)$ respectively were housewives. Also, slightly less than two-thirds $(60 \%, 58 \%)$ respectively of them were Illiterate and basic education.

Table (2): Reveals that those women in the two groups had insignificant differences regarding their mode of previous delivery. Also, the same table illustrates that, the majority (72.5\%) of mothers had a vaginal delivery with episiotomy in which $38.2 \%$ were in study $33.3 \%$ were in control group. As well as slightly less than one quarter $(21.6 \%)$ of them had normal vaginal delivery without episiotomy, in which $11.8 \%$ were in study $9.8 \%$ were in control group. Meanwhile, the minority (5.9\%) of them had instrumental delivery, in which $2 \%$ were in study $3.9 \%$ were in control group.

Table (3): Regarding to method of management of third stage of labor, $94 \%$, of mothers in the study group had active method for management of third stage of labor as compared with $70 \%$ in the control group; with significant difference. Regarding placental condition after delivery; $98 \%$ of mothers in the study group had complete placental tissues, as compared with $80 \%$ in the control group; with significant difference.

Table (4): Regarding the duration of third stage of delivery, it was revealed that the mean duration of third stage of labor was significant longer (19.4 \pm 7.9$)$ in control group than in study group (12.6 \pm 5.3$)$, with the range of duration of third stage of labor from 5 to 38 minutes

Table (5): This part describes uterine tone of mothers immediately after delivery for the end of the first $1 \mathrm{hr}$, after $2 \mathrm{hrs}$, and after $3 \mathrm{hrs}$ of delivery. Regarding to tone of the uterus during the fourth stage of delivery, The rates of contracted uterus after $1,2,3$ hours were significant higher (38\%, $42 \%$ and $100 \%$ respectively)for mothers in the study group a than in control group $(18 \%, 22 \%, 70 \%$ respectively).

Table (6): Regarding the amount of blood loss, immediately after delivery for the end of the first $1 \mathrm{hr}$, after $2 \mathrm{hrs}$, and after $3 \mathrm{hrs}$ of delivery. The mean amount of blood loss after 1, 2, 3 hours were significant lower (350.6, 120.5 and 52.1 respectively) for mothers in the study group than in control group (704.8, 242.4, 62.6 respectively).

Table (7): Regarding the factors that might affect period of discharge, there were statistically significant relationships between mode of delivery $(\mathrm{T}=3.371, \mathrm{P}=$ $0.039)$, duration of third stage of delivery $(\mathrm{T}=0.328, \mathrm{P}=$ 0.001), method of management of third stage of labor $(\mathrm{T}=-3.196, \mathrm{P}=0.002)$, placental condition $(\mathrm{T}=-4.722, \mathrm{P}=$ $0.001)$, presence of tears $(\mathrm{T}=-3.001, \mathrm{P}=0.003)$, and blood transfusion $(\mathrm{T}=8.22, \mathrm{P}=0.001)$, and period of recovery and discharge.

Table (8): Regarding the factors which might affect amount of blood loss after $3 \mathrm{hrs}$ of labor, t-test indicated that there were statistically significant relationships between placental condition ( $\mathrm{T}=-6.29, \mathrm{P}<0.001)$, presence of tears $(\mathrm{T}=-3.97, \mathrm{P}<0.001)$, tone of the uterus $(\mathrm{T}=-8.22$, $\mathrm{P}<0.001$ ), method of management of third stage of labor ( $\mathrm{T}=-3.21, \mathrm{P}=0.002$ ) and amount of blood loss after $3 \mathrm{hrs}$ of delivery. In addition, there was a high statistically positive correlation between duration of third stage of labor ( $\mathrm{T}=0.674, \mathrm{P}=0.001$ ), and amount of blood loss after $3 \mathrm{hrs}$ of labor. On the other hand, one way mean indicated that 
there was no statistically significant relationship between mode of delivery $(\mathrm{T}=0.33, \mathrm{P}=0.72)$, and amount of blood loss after 3 hrs of labor.

\section{Discussion}

The Third stage of labor begins immediately after delivery of the placenta and fetal membranes so, the third stage of labor is the stage of separation and expulsion of the placenta, and fatal membrane the third stage of labor is perhaps the most dangerous stage of labor for the mother. The main dangers postpartum hemorrhage. (Mousa et al., 2008) So the purpose of the study was to implement an evidence-based guideline for caring a woman during the third stage of labor and evaluate the labor outcomes of evidence-based intervention in reduction of complications related to $\mathrm{PPH}$ and deteriorations of maternal conditions.

Regarding maternal age and occupation, the current study revealed that there was no statistically significant difference between two groups. Also, the present study showed that both "maternal age and occupation" are not predictor variables of developing $\mathrm{PPH}$ and increasing the amount of blood loss with insignificant difference between two groups. These findings might be referred to the age of mothers as well as maternal occupation which alone had no effect in developing PPH

Concerning mode of delivery, it is not a predictor variable of amount of blood loss at fourth stage of labor and incidence of PPH. This finding may be due to the fact that normal vaginal delivery without episiotomy, vaginal delivery with episiotomy, or even cesarean section did not affect incidence of PPH. In the present study, the mean amounts of blood loss were $406.25 \pm 167.96 \mathrm{ml}, 314.22 \pm$ $173.45 \mathrm{ml}$, and $492.86 \pm 339.6 \mathrm{ml}$, for mothers who delivered normally, with episiotomy, and cesarean section respectively. This finding is in accordance with those of McDonald et al., (2012), \& Mousa \& Alfiveric (2008), they reported that there's no statistically significant relationship between mode of delivery and incidence of PPH.

The result of the current study revealed that the active method of management of third stage seems to play a crucial role in the amount of blood loss and early recovery and discharge $(\mathrm{T}=3.21, \mathrm{P}=0.002)$. This finding may be due to the active method of management of third stage of labor which tends to decrease the amount of blood loss and incidence of PPH. This is supported by Prendiville et al., (2008), \& Young \& Chong (2004), they found that the prevalence rate of PPH of more than $500 \mathrm{ml}$ is approximately $5 \%$ when active management is used, versus $13 \%$ when management is used. Similarly, the prevalence rate of $\mathrm{PPH}$ is of more than $1000 \mathrm{ml}$ which are approximately $1 \%$ when active management is used, versus $3 \%$ when expectant management is used.

Moreover, John \& Barbara (2010), reported that incomplete placental separation leads to massive PPH and atonic uterus which is congruent with the result of the current study, as placental condition is a predictor variable of the amount of blood loss. This finding may indicate to that incomplete placental separation (retained placental fragments) results in increased amount of blood loss versus to mothers with complete delivered placenta. The mean amounts of blood loss at fourth stage of labor were $323.29 \pm 172.4 \mathrm{ml}$ and $506.2 \pm 188.96 \mathrm{ml}$ for mothers with complete delivered placenta and retained one respectively.

Table (4): revealed that duration of the 3 stage of labor in the two groups and occurrence of PPH: The current study illustrated that, the mean duration of the 3 stage of labor is significant higher in control than study groups. This finding reflected that duration of the 3 stage of labor is a predictor variable of amount of blood loss and incidence of PPH. This finding may be referred to that a prolonged 3rd stage increases the amount of blood loss at this stage. This finding is in agreement with Jackson et al., (2011), and Concetta \& Oteri- Ahmadpour (2006), as they reported that PPH is mostly associated with prolonged second and third stages of labor as well as no use of oxytocics

Finding of the current study revealed that period of recovery and discharge seem to play a very crucial role in clarification of maternal condition. So, the subjects studied for the variables which affect period of recovery and discharge. Mode of delivery is a predictor variable of the period of recovery and discharge. This finding indicate that normal vaginal delivery without episiotomy, vaginal delivery with episiotomy, or even cesarean section affect the period of recovery and discharge. The mean durations of recovery and discharge were $22.12 \pm$ $23.17 \mathrm{hrs}, 27.27 \pm 27.3 \mathrm{hrs}$, and $54.00 \pm 23.1 \mathrm{hrs}$, for mothers who delivered normally, with episiotomy, and cesarean section respectively. This finding is supported by the study of John \& Barbara (2010), which reported that there was clear association between mode of delivery and period of recovery and discharge.

Method of management of third stage of labor seems to be a crucial risk in prolonging both duration of third stage and period of recovery and discharge. In this study, the mean periods of recovery and discharge were $24.03 \pm$ $22.7 \mathrm{hrs}$ and $45.56 \pm 36.75 \mathrm{hrs}$, for mothers having active and expectant method of management respectively, of the third stage of labor. This finding is supported by that of Prendiville et al., (2008), which reported that routine active management is superior to expectant management in controlling blood loss, PPH, and other serious complications of third stage of labor.

Moreover, results of the current study indicate that the rate of incomplete placental separation was significant higher in control group; this result return to women in control group did not receive any educational guideline during the third stage of labor. Regarding the relation between placental condition of women in the study 
sample and their PPH; the present study revealed that placental condition is a predictor variable of period of recovery and discharge. This finding may be attributed to the incomplete placental separation (retained placental fragments) which results in increased period of recovery and discharge versus mothers with complete delivered placenta. The mean periods of recovery and discharge were $22.1 \pm 23.5 \mathrm{hrs}$, and $51.00 \pm 27.77 \mathrm{hrs}$, for the mothers with complete delivered placenta and retained one. This finding is congruent with that of Abd Elmonem (2009), which indicated that incomplete placental separation leads to massive PPH and prolongs the duration of mothers' hospitalization to recover and be discharged.

Finally, the finding of the current study revealed that mode of delivery is a predictor variable of maternal outcome. This finding may indicate that most of mothers who delivered normally without episiotomy recovered and were discharged with no need of surgery, while a minority of them had partial hysterectomy. On the other hand, less than two thirds of mothers who delivered by cesarean section recovered and were discharged, and one quarter of them died. This finding is supported by that of Reyal et al., (2006) which revealed that there was highly statistically significant relation between mode of delivery and maternal outcome.

\section{Conclusion}

This study concluded that, the application of the program nursing with efficiency in nursing based on evidence in the third stage is particularly important in reducing postpartum hemorrhage and some health problems associated with this period, such as laceration of the perineum and cutting umbilical cord as well as the delay in placental separation noted in the study sample. A highly statistically significance of this stage of birth and placental complete, and the amount of blood lost is very low after birth. The group applied tutorial was less time of placental separation, and the amount of blood lost with the first two hour of the postpartum.

\section{Recommendations}

In the light of the results of this study, the following recommendations are provided

- For every woman who wants to keep health intact and try to pass the process of delivery successfully, the use of implemented guideline of based practices in management of third stage of labor was recommended.

- Efforts to reduce PPH should not only be directed to proper management of labor but also, to training and retraining of health care providers and alternative health care workers for early referral of patients with prolonged labor.
- Training programs for nurses midwives about essential care during third stage of labor

Further recommendation

- Pay attention to pregnant woman about proper antenatal care to reduce performance of surgical intervention.

- Others researches could be used on the same items and should be on a large population in order to generalize the findings.

\section{References}

1. Abd Elmonem, R., (2009): Comparative study between misoprotal and syntometrine. Faculty of medicine cairo university, 92-120.

2. Barwick, M., (2009). Knowledge transfer and implementation of evidence-based practices in children's mental health. Ontario Canada: Children's Mental Health Ontario.

3. Berg, C., Knight, M., Callaghan, W., \& Alexander, S., (2009): Trends in postpartum hemorrhage in high resource countries: a review and recommendations from the International Postpartum Hemorrhage Collaborative Group. BMC pregnancy and childbirth, 9(1), 55.

4. Center for Mental Health services (2010): Predictors of women's health of the childbirth experience. Journal of Obstetric, Gynecology, Neonatal nursing 37(1) 24-34.

5. Cheng Y., Caughey, A., Khan, F., \& Razi, M., (2010): Normal labor and delivery. Retrieved October 23, from http:// www.emidicine.com /med/topic3239.html

6. Concetta, R., \& Otri-Ahmed Pour, D., (2006): Management of past partum hemorrhage. Available at: http://www.pubmed.com

7. Cunnungham F., McDonald, P., Gant, N., \& Gilstrap L., (2009): Williams Obstetrics, 21st edition, MC Graw -Hill Co., New York, 41-52

8. Donna, L., (2008): Managing excessive hemorrhage during labor \& postpartum period. Journal of obstetrics \& gynecologic \& Newnetal Nursing 36(5): 490-496

9. Jackson, K., Allbert, J., \& Schemmer, G., (2011): A randomized controlled trial comparing administration before and after placental delivery in prevention of post partum hemorrhage. Located at: http://www.emedicine.com/med/topics3568.htm

10. Johnson, T., Callister, L., Freebom, D., \& Huender, (2009): Clinical evidence for common practices during labor MCN: American Journal of maternal-child nursing, 30(6), 356-63.

11. John, D., Barbara, C., \& Winter, H., (2010): Postnatal care: Evidence and guideline for management. Edinburgh: Churchill. Livingstone. 
12. Kevin J., (2009): Routine episiotomy in modern obstetrics. Is it necessary/ (article in polish) women's health, rep. Aug; (1):72-80.

13. Leff, N., Hansen, P., \& Leipert, S., (2009): Standard of Care, Quality Improvement. Journal of Advanced Nursing, 76(21), 93-95.

14. Leifer, G., \& Mayberry, L., (2009): Introduction to maternity and practice nursing. 3rd rd. Philadelphia, W.B. Saunders, 125-159.

15. Levin, R., Felman, H., (2012): Teaching evidence-based practice in nursing: a guide for academic and clinical setting. NewYork: Springer, 550-596. available at: http://www.google.com

16. Maternal health survey (2010): Foundation of maternal - newborn nursing. WB. Saunders.company.

17. McDonald, S., Prendiville, W., \& Elbourne, D., (2012): Active versus expectant management of the third stage of labor. Cochrane data base. available

at: http://www.emedicine.com/medtopics3568-htm

18. Milasionvic, L., Kapamadzija, A., Dobric, L., \& Petrov, D., (2009): Postpartum: Incidence and etiology, Medicines Kipregled, 394-399.

19. Mosua, H., \& Alfirevice, Z., (2008): Treatment of post partum hemorrhage. http://www.ncbinlm. nih.com 6-14

20. Mousa H., Mckinely C., Thang J., \& Nielsen, M., (2008): Expectant management of the third stage of labor. American Journal of obstet. Gyneco June; 6:180.

21. Omyma, S., (2010): Efficacy of different doses of sublingual misoprostal versus the standard oxytocics in the management of the third stage of labor Msc in obstetrics and gynecology, ElMinia University (09), 77-78.

22. Prendiville W., Elbourne D., \& McDonald S., (2008): Active versus expectant management of the third stage of labor, Cochrane library, Issue I., Update Software, Oxford 548-549.

23. Reyal, B., Marcia, L., Batricia, W., \& Michete, R., (2006): Maternal-newborn nursing and woman's healthcare. 7th ed. Paerson Education, 991-1009.

24. World health organization (WHO), (2005): Managing complications in pregnancy and childbirth available at http:// www. childinfo. org/maternal-mortality

25. World health organization (WHO), (2009): Maternal mortality in 2005 developed by WHO, UNISEF and UNFPA, Geneva, WHO available at http://wikipedia.org

26. Young, D., \& Chong, Y., (2004): Current strategies for the prevention of postpartum hemorrhage in the third stage available at http://www.pubmed.com 